\title{
POSTOPERATIVE ANALGESIA WITH INTRAPERITONEAL ROPIVACAINE WITH AND WITHOUT DEXMEDETOMIDINE AFTER TOTAL LAPAROSCOPIC HYSTERECTOMY: A RANDOMIZED, DOUBLE-BLIND, CONTROLLED TRIAL
}

\author{
RANJITA ACHARYA*, DAISY KARAN, MEGHA KHETAN
}

Department of Anaesthesia, Sum Hospital, Bhubaneswar, Odisha, India. Email: drranjitaacharya@gmail.com

Received: 29 July 2016, Revised and Accepted: 24 August 2016

\begin{abstract}
Objective: In this advanced era of surgery, laparoscopic hysterectomy operations are very commonly practiced by surgeons. It reduces trauma, morbidity, and health-care costs, ensuring early discharge. However, the early post-operative pain experienced by patients may sometimes negate all the advantages of a laparoscopic procedure. Intraperitoneal (IP) instillation of local anesthetics has been proposed to decrease post-operative pain after laparoscopic surgeries. Additives to local anesthetics like $\alpha$-2 agonists such as clonidine and dexmedetomidine prolong the duration of analgesia. Therefore, this randomized, prospective, controlled study was conducted to compare the analgesic efficacy of IP ropivacaine with or without dexmedetomidine for postoperative analgesia after total laparoscopy hysterectomy.
\end{abstract}

Methods: At the end of laparoscopic hysterectomy, in a double-blind, randomized manner, one of the following injections was given intraperitoneally. The patients were allocated into the following two groups: The patients in ropivacaine group (R group) ( $\mathrm{N}=40$ ) were given 38 ml of $0.2 \%$ ropivacaine plus $2 \mathrm{ml}$ of normal saline (NS) and the patients in ropivacaine plus dexmedetomidine group (RD group) ( $\mathrm{N}=40$ ) were given $38 \mathrm{ml}$ of $0.2 \%$ ropivacaine combined with $0.5 \mu \mathrm{g} / \mathrm{kg}$ dexmedetomidine (diluted in $2 \mathrm{ml} \mathrm{NS}$ ) through trocars. All the patients were given diclofenac sodium when they had a pain score of 4 on visual analog scale (VAS).

Results: VAS score at different time intervals was significantly lower after the second postoperative hour, time to first request of analgesia (minutes) was longest ( $487.7 \pm 40.96$ vs. $242.5 \pm 19.84$ ), and the total analgesic consumption (mg) was lowest (61.88 \pm 37.55 vs. $183.75 \pm 44.78$ ) in RD group than in R group.

Conclusion: The antinociceptive effects of the IP instillation of ropivacaine in combination with dexmedetomidine are superior to ropivacaine alone in laparoscopic hysterectomy cases.

Keywords: Dexmedetomidine, Ropivacaine, Laparoscopic Hysterectomy.

(C) 2016 The Authors. Published by Innovare Academic Sciences Pvt Ltd. This is an open access article under the CC BY license (http://creativecommons. org/licenses/by/4. 0/) DOI: http://dx.doi.org/10.22159/ajpcr.2016.v9s3.14396

\section{INTRODUCTION}

Laparoscopic procedures have revolutionized gynecological surgeries and have almost replaced traditional open surgeries. It has many advantages over open surgeries, with smaller and more cosmetic incisions, reduced blood loss, reduced pain, early mobility, and early enteral feed, hence there will be reduced hospital stay [1,2]. However patients undergoing laparoscopic surgeries experience early postoperative pain which may require proper attention. Pain intensity usually peaks during the first postoperative hours [3]. Pain following laparoscopy is multifactorial, with visceral pain being worse than abdominal wall pain. Pain results from stretching of intra-abdominal cavity, peritoneal inflammation, and diaphragmatic irritation caused by residual carbon dioxide in peritoneal cavity [4-6]. Providing adequate postoperative analgesia while meeting the criteria for discharge on the same day is a challenge.

Recently, the use of local anesthetics for postoperative pain relief in laparoscopy has become a popular technique. It provides adequate analgesia without any side effect unlike intravenous opioids. Intraperitoneal (IP) instillation of local anesthetic agents alone [7] or in combination with opioids [8,9] and $\alpha-2$ agonists such as clonidine [10] and dexmedetomidine [11] has been found to reduce post-operative pain following laparoscopic gynecological surgeries.

This prospective controlled study was conducted to compare the analgesic efficacy of IP ropivacaine with or without dexmedetomidine for postoperative analgesia after total laparoscopic hysterectomy.

\section{METHODS}

This is a prospective randomized controlled study conducted from November 2015 to June 2016 at IMS and SUM Hospital with due consent of patients. A total of 80 patients aged 45-65 years of the American society of Anesthesiologists physical status score (ASA) I and II, scheduled for total laparoscopic hysterectomy, were included in the study. Exclusion criteria were as follows; hypersensitivity to ropivacaine, acute cholecystitis, weight $<45 \mathrm{~kg}$ or $>100 \mathrm{~kg}$, history of previous abdominal surgery, ASA class 3 or 4 , endocrine disorders such as diabetes mellitus, and patients with severe cardiac or pulmonary diseases.

Patients were randomly divided into two equal groups $(n=40)$. Randomization was done by computer-generated random numbers sealed in envelope, which was distributed by resident doctors during Pre-anaesthetic check up (PAC), in which patients received

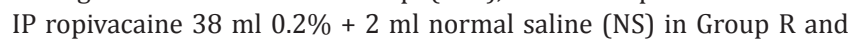

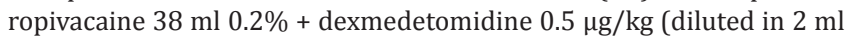
NS) in Group RD before removal of trocar at the end of surgery.

A conventional balanced general anesthesia was administered to all patients. Glycopyrrolate $(0.2 \mathrm{mg})$ and midazolam $(0.03 \mathrm{mg} / \mathrm{kg})$ were given as premedication. General anesthesia was induced with propofol and fentanyl $(2 \mu \mathrm{g} / \mathrm{kg})$. Tracheal intubation was facilitated with vecuronium $(0.06 \mathrm{mg} / \mathrm{kg})$. Anesthesia was maintained with $\mathrm{O}_{2}$ and air (50-50\%) and isoflurane at 1 Minimum Alveolar Concentration (MAC). Muscle relaxation was maintained by additional doses of vecuronium 
as and when required. All patients received ranitidine and ondansetron as antiemetics. Monitoring included heart rate, respiratory rate, continuous ECG, NIBP, $\mathrm{SpO}_{2}$ and $\mathrm{EtCO}_{2}$. All surgeries were performed in Trendelenburg position. Intra-abdominal pressure of $\mathrm{CO}_{2}$ was kept stable at $10-12 \mathrm{mmHg}$ in all cases. A volume of $40 \mathrm{ml}$ drug solution was given as IP instillaion. After peritoneal wash and suction, $10 \mathrm{ml}$ drug solution was instilled on the inferior aspect of each diaphragm and the rest $20 \mathrm{ml}$ at the operative site through the umbilical port.

The quality of analgesia was determined by visual analog scale (VAS) for $24 \mathrm{hrs}$. Post-operative pain scores were recorded by independent resident doctors at $1 / 2 \mathrm{hr}, 1 \mathrm{hr}, 2 \mathrm{hrs}, 4 \mathrm{hrs}, 8 \mathrm{hrs}, 12 \mathrm{hrs}$, and $24 \mathrm{hrs}$. Post-operative analgesia was standard in all groups. When VAS score was $>4$, patients were given diclofenac sodium (75 mg IV). Time to first request of analgesia, total dose of analgesic required in the first $24 \mathrm{hrs}$, and any adverse effect such as nausea and vomiting and shoulder tip pain were noted.

Statistical analysis was performed using SPSS software version 12 . Continuous data were described as mean \pm standard deviation (SD), and Categorical data were presented as absolute numbers or percentage. Continuous variables were compared using Student's independent $t$-test. Chi-square tests were used to match the demographic data of two groups. All data were presented as mean $\pm \mathrm{SD}$, percentage (\%), or number

\section{Observation}

The two groups were comparable for age, weight, and duration of surgery (Table 1). All patients in both groups underwent laparoscopic hysterectomies successfully without any requirement to conversion to open operation; hence, there were no dropouts from any group.

The mean VAS scores of group RD were significantly lower at all time intervals except till the $2^{\text {nd }} \mathrm{hr}$ postoperatively when compared to group $\mathrm{R}(\mathrm{p}<0.05)$ (Table 2). At $24^{\text {th }} \mathrm{hr}$, the difference between VAS scores of the two groups was statistically significant $(\mathrm{p}=0.00)$ (Table 2 ).

Time to requirement of the first rescue analgesia was $487.7 \pm 40.96$ minutes in group RD as compared to $242.5 \pm 19.84$ minutes in group $\mathrm{R}(\mathrm{p}=0.00$ ) (Table 3$)$. The mean total consumption of diclofenac in $\mathrm{RD}$ group was at an average of $61.88 \pm 37.55 \mathrm{mg}$, while in ropivacaine group, it was $183.75 \pm 44.78 \mathrm{mg}$, which was statistically significantly high $(\mathrm{p}=0.00)$ (Table 3). All patients received rescue analgesia in group $\mathrm{R}$ at various time intervals whereas only $62 \%$ of the patients in group RD received rescue analgesia.

Table 1: Demographic data

\begin{tabular}{llll}
\hline Groups & Age (years) & Weight (kg) & $\begin{array}{l}\text { Duration of } \\
\text { surgery (minute) }\end{array}$ \\
\hline $\mathrm{R}(\mathrm{n}=40)$ & $57.33 \pm 5.6$ & $57.63 \pm 5.6$ & $110.55 \pm 9.4$ \\
$\mathrm{RD}(\mathrm{n}=40)$ & $56.55 \pm 5.3$ & $58.05 \pm 5.32$ & $110.83 \pm 2.2$ \\
$\mathrm{p}$ & 0.52 & 0.4 & 0.85 \\
\hline
\end{tabular}

n: Number of patients, Kg: Kilograms, values are expressed in mean \pm SD, min: Minutes, SD: Standard deviation

Table 2: Postoperative VAS scores at $1 / 2 \mathrm{hr}, 1 \mathrm{hr}, 2 \mathrm{hrs}, 4 \mathrm{hrs}$, 8 hrs, 12 hrs, and 24 hrs

\begin{tabular}{llll}
\hline VAS score timing & $\mathbf{R}(\mathbf{n}=\mathbf{4 0})$ & $\mathbf{R D}(\mathbf{n}=\mathbf{4 0})$ & $\mathbf{p}$ \\
\hline $1 / 2 \mathrm{hr}$ & $0.33 \pm 0.47$ & $0.25 \pm 0.44$ & 0.465 \\
$1 \mathrm{hr}$ & $1.83 \pm 0.54$ & $1.58 \pm 0.59$ & 0.054 \\
$2 \mathrm{hr}$ & $2.23 \pm 0.66$ & $0.2 .10 \pm 0.67$ & 0.404 \\
$4 \mathrm{hrs}$ & $4.13 \pm 0.72$ & $1.48 \pm 0.71$ & 0.000 \\
$8 \mathrm{hrs}$ & $2.35 \pm 0.74$ & $1.75 \pm 1.28$ & 0.012 \\
$12 \mathrm{hrs}$ & $4.25 \pm 0.54$ & $1.98 \pm 1.1$ & 0.001 \\
$24 \mathrm{hrs}$ & $2.15 \pm 0.66$ & $1.6 \pm 0.71$ & 0.001 \\
\hline
\end{tabular}

VAS: Visual analog scale, $\mathrm{n}$ : Number of patients; values are expressed in mean \pm SD, SD: Standard deviation
The side effects such as nausea and vomiting were also less in RD group than in ropivacaine group, but the difference noted was not statistically significant $(p>0.05)$ (Table 4).

\section{DISCUSSION}

Laparoscopic surgeries are nowadays practiced as day care procedures. Thus, providing adequate post-operative pain relief is considerably important, as patients need to be discharged on the same day or another day. Previous studies prove that though laparoscopy is a minimally invasive procedure, certain degree of pain is still experienced by patients. Pain can be multifactorial arising from incision site (somatic pain), from surgical site (visceral pain), and due to pneumoperitoneum (referred pain) [12]. Out of the different regimens proposed for post-operative pain such as intravenous NSAIDS, opioids, and local infiltration, IP infiltration of local anesthetic has been chosen by many surgeons as an effective modality. The rationale for this route is that visceral nociceptive conduction is blocked. The local anesthetic inhibits nociception by affecting nerve membrane-associated proteins and by inhibiting the release and action of prostaglandins and other agents that sensitize the nociceptors and contribute to inflammation [11]. However, absorption from large peritoneal surface may also occur and this may be a further mechanism of analgesia. Local anesthetics have been administered into peritoneal cavity during laparoscopic cholecystectomy and gynecological laparoscopy for sterilization and diagnosis, in addition to open abdominal procedure such as total abdominal hysterectomy [13]. This technique was first evaluated in patients undergoing gynecological laparoscopic surgery [14]. Its application in laparoscopic cholecystectomy was initially examined in a randomized trial in 1993 [15]. The main advantage of using local anesthetics is that they do not have the adverse effect of opioids, which may delay recovery and discharge from hospital.

Bupivacaine has been used most widely for treating post-operative analgesia after laparoscopic cholecystectomy. Ropivacaine , a new longacting amide local anesthetic, is chemically related to bupivacaine, but it has been shown to be less toxic to cardiac and central nervous systems [16]. Kucuk et al. [9] reported benefit in terms of both postoperative pain and analgesic consumption using $150 \mathrm{mg}$ ropivacaine. IP instillation of $150 \mathrm{mg}$ ropivacaine during gynecological laparoscopy produced statistically significant 24 hrs morphine-sparing effect compared with placebo. Gupta et al. concluded that ropivacaine $70 \mathrm{ml}(0.25 \%)$ infiltrated into cholecystectomy wounds significantly decreases wound pain and increases time until the first request of post-operative analgesia, without any side effect attributable to ropivacaine [17]. Labaille et al. used $100 \mathrm{mg}$ of ropivacaine infiltrated intraperitoneally and concluded it to be the optimal dose for reducing

Table 3: Comparison of analgesic requirements

\begin{tabular}{llll}
\hline Parameters & $\mathbf{R}(\mathbf{n}=\mathbf{4 0 )}$ & $\mathbf{R D}(\mathbf{n}=\mathbf{4 0 )}$ & $\mathbf{p}$ \\
\hline $\begin{array}{l}\text { Number of patients given } \\
\text { rescue analgesia (\%) }\end{array}$ & $40(100)$ & $25(62.5)$ & 0.001 \\
$\begin{array}{l}\text { Mean time for the first } \\
\text { dose (minutes) }\end{array}$ & $242.5 \pm 19.84$ & $487.7 \pm 40.96$ & 0.001 \\
$\begin{array}{l}\text { Mean total dose (mg) in } \\
\text { (183.75 } \pm 44.78\end{array}$ & $61.88 \pm 37.55$ & 0.001
\end{tabular}

$24 \mathrm{hrs}$

$\mathrm{n}$ : Number of patients; \%: Percentage of patients in each group, mg: Milligrams of diclofenac, values are expressed in mean \pm SD, SD: Standard deviation

Table 4: Incidence of side effects

\begin{tabular}{llll}
\hline $\begin{array}{l}\text { Post-operative } \\
\text { complaints }\end{array}$ & $\begin{array}{l}\text { Group } \\
\mathbf{R}(\mathbf{n}=\mathbf{4 0})(\mathbf{\%})\end{array}$ & $\begin{array}{l}\text { Group } \\
\mathbf{R D}(\mathbf{n}=\mathbf{4 0 )} \mathbf{( \% )}\end{array}$ & $\mathbf{p}$ \\
\hline Nausea & $8(20)$ & $2(5)$ & 0.087 \\
Vomiting & $3(7.5)$ & 0 & 0.07 \\
Shoulder tip pain & $2(5)$ & 0 & 0.15 \\
\hline
\end{tabular}

n: Number of patients, \%: Percentage of patients in each group 
pain after laparoscopic cholecystectomy [8]. One previous study by Goldstein et al. reported that the IP instillation of $20 \mathrm{~mL}$ of either $0.5 \%$ bupivacaine or $0.75 \%$ ropivacaine prevented postoperative pain and decreased the need for postoperative analgesia, when compared with placebo in patients undergoing laparoscopic gynecologic [18]. Papas-Gogos et al. used $155 \mathrm{mg}$ of ropivacaine, of which $80 \mathrm{mg}$ was infiltrated intraperitoneally and the rest was infiltrated at trocar wounds. They observed adequate pain relief [19]

In our study, we used $76 \mathrm{mg}$ ropivacaine $(0.2 \%)$ for IP instillation in one group and mixed it with dexmedetomidine $(0.5 \mu \mathrm{g} / \mathrm{kg})$ in another group of patients.

Dexmedetomidine is a highly lipophilic $\alpha 2$ agonist. Its antinociceptive effect occurs at dorsal root neuron level. Here, it blocks the release of substance $\mathrm{P}$ in nociceptive pathway through the action of inhibitory $\mathrm{C}$ protein, which increases the conductance through $\mathrm{K}+$ channels [20] Dexmedetomidine enhances both central and peripheral neural blockade by local anesthetics [21]. Its peripheral neural blockade is due to its binding to $\alpha 2 \mathrm{a}-\mathrm{AR}$ antibody. Because of the high lipophilic nature of dexmedetomidine, it acts over the peritoneal neural receptors and blocks the nociceptive stimuli. Memis et al. [22] in 2005 studied the effects of tramadol and clonidine added to IP bupivacaine on postoperative pain in total abdominal hysterectomy and found it to be better than bupivacaine alone. Very few studies in literature have examined the analgesic effect of IP dexmedetomidine. Ahmed et al. [23] compared meperidine or dexmedetomidine in combination with bupivacaine $(0.25 \%)$ in gynecological laparoscopic surgery and concluded that dexmedetomidine group significantly decreased post-operative analgesic requirement. Results of our study correlate with the above study.

On analysis of mean scores of group R and group RD, it was observed that group RD had better pain relief till $24 \mathrm{hrs}$ postoperatively and this was statistically significant $(\mathrm{P}=0.05)$, except at $1 / 2 \mathrm{hr}$, at $1 \mathrm{hr}$, and $2 \mathrm{hrs}$ postoperatively when pain scores were not statistically different. Shukla et al. had done the same study in laparoscopic cholecystectomy and concluded that IP instillation of dexmedetomidine in combination with bupivacaine gives better pain relief and reduces analgesic requirement as compared to bupivacaine alone [24].

Table 3 shows that in group R, patients required the first dose of rescue analgesia by $242.5 \pm 19.84$ minutes, whereas in group RD, analgesia stayed for nearly $487.7 \pm 40.96$ minutes. However, the VAS score in group $\mathrm{R}$ was low after $4^{\text {th }} \mathrm{hr}$; this may be due to the administration of diclofenac to these patients after $4^{\text {th }} \mathrm{hr}$ postoperatively.

In patients receiving ropivacaine and dexmedetomidine, only few patients required the second dose of rescue analgesia (Table 4). The mean dose of diclofenac consumption was significantly higher in group $R$ $(183.75 \pm 44.78 \mathrm{mg})$ than in group RD $(61.88 \pm 37.55 \mathrm{mg})$. These findings suggest that adding dexmedetomidine to ropivacaine intraperitoneally significantly decreases analgesic requirement. The above results were in agreement with that of Memis et al. and Ahmed et al., but on contrast, Memis et al. in their study found higher doses in clonidine group than tramadol group. In the present study, dexmedetomidine shows better results which might be due to its high selectivity than clonidine.

Regarding adverse effects, nausea and vomiting were found in 8 patients in group $\mathrm{R}$ and 2 patients in group RD. The result was statistically insignificant.

Shoulder tip pain after laparoscopic cholecystectomy occurs in 35-63\% of the patients [18]. It occurs after diaphragmatic stretching with phrenic nerve neuropraxia. The incidence of shoulder pain is markedly lower in laparoscopic hysterectomy when compared to laparoscopic cholecystectomy [25]. In our study, shoulder tip pain was observed only in 2 patients in group R and none in group RD. Joris et al obtained similar results using bupivacaine concluding that using bupivacaine intraperitoneally decreases incidence of shoulder pain for $24 \mathrm{hrs}$ postoperatively.

\section{CONCLUSION}

IP instillation of ropivacaine and dexmedetomidine combination is an easy and effective mode of providing postoperative analgesia in laparoscopic hysterectomy for a longer period and is superior to ropivacaine alone without any significant increase in adverse events.

\section{REFERENCES}

1. Lahmann B, Adrales GL, Mastrangelo MJ Jr, Schwartz RW Laparoscopic cholecystectomy-technical considerations. Curr Surg 2002;59(1):55-8.

2. Zucker KA, Bailey RW, Flowers J. Laparoscopic management of acute and chronic cholecystitis. Surg Clin North Am 1992;72(5):1045-67.

3. Joris J, Thiry E, Paris P, Weerts J, Lamy M. Pain after laparoscopic cholecystectomy: Characteristics and effect of intraperitoneal bupivacaine. Anesth Analog 1995;81(2):479-84.

4. Cuschieri A. Laparoscopic cholecystectomy. J R Coll Surg Edinb 1999;44(3):187-92.

5. Alexander JI. Pain after laparoscopy. Br J Anaesth 1997;79:369-78.

6. Gupta R, Bogra J, Kothari N, Kohli M. Postoperative analgesia with intraperitoneal fentanyl and bupivacaine: A randomized control trial. Can J Med 2010;11-11.

7. Marks JL, Ata B, Tulandi T. Systematic review and metaanalysis of intraperitoneal instillation of local anesthetics for reduction of pain after gynecologic laparoscopy. J Minim Invasive Gynecol 2012;19(5):545-53.

8. Labaille T, Mazoit JX, Paqueron X, Franco D, Benhamou D. The clinical efficacy and pharmacokinetics of intraperitoneal ropivacaine for laparoscopic cholecystectomy. Anesth Analg 2002;94(1):100-5

9. Kucuk C, Kadiogullari N, Canoler O, Savli S. A placebo-controlled comparison of bupivacaine and ropivacaine instillation for preventing postoperative pain after laparoscopic cholecystectomy. Surg Today 2007;37(5):396-400.

10. Kahokehr A, Sammour T, Soop M, Hill AG. Intraperitoneal local anaesthetic in abdominal surgery - A systematic review. ANZ J Surg 2011;81(4):237-45

11. Liu SS, Hodgson PS. Local anaesthetics. In: Barash PG, Cullen BF, Stoelting RK, editors. Clinical Anaesthesia. $4^{\text {th }}$ ed. Philadelphia, PA: Lippicott Williams \& Wilkins; 2001. p. 449-69.

12. Kim TH, Kang H, Park JS, Chang IT, Park SG. Intraperitonea ropivacaine instillation for post-operative pain relief after laparoscopic cholecystectomy. J Korean Surg Soc 2010;79:130-6.

13. Møiniche S, Jørgensen H, Wetterslev J, Dahl JB. Local anesthetic infiltration for postoperative pain relief after laparoscopy: A qualitative and quantitative systematic review of intraperitoneal, port-site infiltration and mesosalpinx block. Anesth Analg 2000;90(4):899-912.

14. Narchi P, Benhamou D, Fernandez H. Intraperitoneal local anaesthetic for shoulder pain after day-case laparoscopy. Lancet 1991;338(87828783):1569-70

15. Jadad AR, Moore RA, Carroll D, Jenkinson C, Reynolds DJ, Gavaghan DJ, et al. Assessing the quality of reports of randomized clinical trials: Is blinding necessary? Control Clin Trials 1996;17(1):1-12.

16. Moller R, Covino BG. Cardiac electrophysiologic properties of bupivacaine and lidocaine compared with those of ropivacaine, a new amide local anesthetic. Anesthesiology 1990;72(2):322-9.

17. Gupta A. Local anaesthesia for pain relief after laparoscopic cholecystectomy - A systematic review. Best Pract Res Clin Anaesthesiol 2005;19(2):275-92.

18. Goldstein A, Grimault P, Henique A, Keller M, Fortin A, Darai E. Preventing postoperative pain by local anaesthetic instillation after laparoscopic gynecologic surgery: A placebo controlled comparision of bupivacaine and ropivacaine. Anesth Analg 2000;91(2):403-7.

19. Pappas-Gogos G, Tsimogiannis KE, Zikos N, Nikas K, Manataki A, Tsimoyiannis EC. Preincisional and intraperitoneal ropivacaine plus normal saline infusion for postoperative pain relief after laparoscopic cholecystectomy: A randomized double-blind controlled trial. Surg Endosc 2008;22(9):2036-45.

20. Kamibayashi T, Maze M. Clinical uses of alpha2 - Adrenergic agonists. Anesthesiology 2000;93(5):1345-9.

21. Kanazi GE, Aouad MT, Jabbour-Khoury SI, Al Jazzar MD, Alameddine MM, Al-Yaman R, et al. Effect of low-dose dexmedetomidine or clonidine on the characteristics of bupivacaine spinal block. Acta Anaesthesiol Scand 2006;50(2):222-7.

22. Memis D, Turan A, Karamanlioglu B, Tükenmez B, Pamukçu Z. The effect of tramadol or clonidine added to intraperitoneal bupivacaine on 
postoperative pain in total abdominal hysterectomy. J Opioid Manag 2005;1(2):77-82.

23. Ahmed B, Elmawgoud AA, Dosa R. Antinociceptive effect of ( $\dot{\alpha}-2$ adrenoceptor agonist) dexmedetomidine vs meperidine, topically, after laproscopic gynecologic surgery. J Med Sci 2008;8:400-4.

24. Shukla U, Prabhakar T, Malhotra K, Srivastava D, Malhotra K Intraperitoneal bupivacaine alone or with dexmedetomidine or tramadol for post-operative analgesia following laparoscopic cholecystectomy: A comparative evaluation. Indian J Anaesth 2015;59(4):234-9.

25. Louizos AA, Hadzilia SJ, Leandros E, Kouroukli IK, Georgiou LG, Bramis JP. Postoperative pain relief after laparoscopic cholecystectomy: A placebo-controlled double-blind randomized trial of preincisional infiltration and intraperitoneal instillation of levobupivacaine $0.25 \%$. Surg Endosc 2005;19(11):1503-6. 